Relations industrielles

Industrial Relations

\title{
Un Code provincial du travail
}

\section{Antonio Barrette}

Volume 1, numéro 6, février 1946

URI : https://id.erudit.org/iderudit/1023934ar

DOI : https://doi.org/10.7202/1023934ar

Aller au sommaire du numéro

Éditeur(s)

Département des relations industrielles de l'Université Laval

ISSN

0034-379X (imprimé)

1703-8138 (numérique)

Découvrir la revue

Citer cet article

Barrette, A. (1946). Un Code provincial du travail. Relations industrielles /

Industrial Relations, 1(6), 5-5. https://doi.org/10.7202/1023934ar

Tous droits réservés @ C Département des relations industrielles de l’Université Laval, 1946
Ce document est protégé par la loi sur le droit d'auteur. L'utilisation des services d'Érudit (y compris la reproduction) est assujettie à sa politique d'utilisation que vous pouvez consulter en ligne.

https://apropos.erudit.org/fr/usagers/politique-dutilisation/ 


\title{
UN CODE PROVINCIAL DU TRAVAIL
}

\author{
N.D.L.R. A titre documentaire nous reproduisons ci-dessous un extrait d'une conférence prononcée, \\ le 16 janvier, par l'Honorable Antonio Barrette, ministre du Travail, \\ province de Québec
}

" Maintenant que nous entrons dans la période de transition et que nous devons revenir à une situation normale, il importe d'examiner la question d'un code national du travail, question qui soulève présentement - beaucoup d'intérêt.

Les industries de guerre n'existant plus, le gouvernement fédéral n'a plus les mêmes motifs d'intervention, et tout ce qui concerne les relations ouvrières et industrielles, la conciliation et d'arbitrage, la fixation des salaires et les négociations collectives, doivent être à l'avenir sous le contrôle exclusif des provinces.

Il apparaît clairement, si on réfère à l'Acte de l'Amérique britannique du Nord, que la plupart des problèmes relatifs aux relations capital-travail sont du domaine provincial. Les paragraphes 13,14 et 15 de l'article 92 de l'Acte précisent les pouvoirs des provinces dans ces termes:

“ 92. Dans chaque province, la Législature pourra exclusivement faire des lois relatives aux matières tombant dans les catégories de sujets ci-dessous énumérés :

13. - La propriété et les droits civils;

14. - L'administration de la justice y compris la procédure en matières civiles.

15. - L'infliction de punitions dans le but de faire exécuter toute loi de la province dans le cadre de sa juridiction. "

Or, le problème des relations capital-travail pose particulièrement des questions d'ordre civil :

a) le contrat de louage de service;

b) le contrat d'apprentissage;

c) la fixation, par décret, des salaires minima;

d) la durée du travail; e) la conciliation et l'arbitrage des conflits d'intérêts;

f) le contrat collectif de travail et les procédures relatives à sa négociation.

Toutes ces questions relèvent du droit civil et, conséquemment sont de la juridiction exclusive de la province. Le Conseil Privé a rendu jugement dans ce sens.

Quand on demande au gouvernement fédéral la promulgation d'un Code national de relations ouvrières, on ne fait pas malheureusement les distinctions nécessaires sur les juridictions respectives de l'autorité fédérale et de l'autorité provinciale, juridictions qui sont délimitées par l'Acte de l'Amérique britannique du Nord, interprétées par le Conseil Privé, après avoir été l'objet d'un pacte entre les provinces.

Promulguer un Code de relations ouvrières complet, c'est surtout légiférer en matières civiles.

Un Code de relations ouvrières pose le principe du droit d'association, celui de la liberté d'action syndicale, réfère aux négociations collectives de travail, détermine la procédure de fixation des salaires, de la durée du travail, des vacances payées, traite de la réglementation de l'apprentissage, oblige enfin à l'établissement d'une procédure de conciliation et d'arbitrage des conflits d'intérêts.

Nous avons toutes raisons de déclarer que les organismes provinciaux actuels répondent aux besoins de l'heure et sont éminemment qualifiés pour répondre aux besoins de l'avenir, en y faisant, s'il y a lieu, des améliorations appropriées que nous avons le pouvoir de réaliser.

Il ne s'agit pas, ici, d'une question de politique partisane mais de politique sociale qui met en jeu l'autonomie de la province, son avenir économique, cultural et social.» 